\section{Case Reports in Neurology}

Case Rep Neurol 2021;13:72-76

DOI: 10.1159/000511956

Published online: February 4, 2021
(C) 2021 The Author(s)

Published by S. Karger AG, Basel www.karger.com/crn

This article is licensed under the Creative Commons Attribution-NonCommercial 4.0 International License (CC BY-NC) (http://www.karger.com/Services/OpenAccessLicense). Usage and distribution for commercial purposes requires written permission.

\title{
A Severe Course of Relapsing- Remitting Acute-Onset Chronic Inflammatory Demyelinating Polyneuropathy in a Young Man
}

\author{
Anna P. Patnaik ${ }^{a} \quad J o s e p h$ Mininni ${ }^{b} \quad$ Neil C. Porter ${ }^{c} \quad N^{2}$ icholas A. Morris ${ }^{c}$ \\ aDepartment of Medicine, Johns Hopkins University School of Medicine, \\ Baltimore, MD, USA; 'b Department of Pathology, University of Maryland School of \\ Medicine, Baltimore, MD, USA; 'Department of Neurology, University of Maryland School \\ of Medicine, Baltimore, MD, USA
}

\section{Keywords}

Chronic inflammatory demyelinating polyneuropathy · Guillain-Barré syndrome ·

Demyelinating polyneuropathy

\begin{abstract}
Acute-onset chronic inflammatory demyelinating polyneuropathy (A-CIDP) is an immune mediated neuropathy characterized by progressive weakness and sensory impairment lasting over 2 months. Guillain-Barré-Strohl syndrome (GBS) is an immune mediated polyneuropathy with a similar presentation often over less than 4 weeks. While some have argued for the existence of recurrent GBS, most classify the syndrome as a form of relapsing-remitting CIDP. However, there are cases of GBS with treatment-related fluctuations that must be distinguished from ACIDP as patients with A-CIDP require long-term immunotherapy. In this case report, we discuss a patient with multiple relapses over 3 years, who is more likely to have A-CIDP. His ganglioside profile, which has rarely been reported in A-CIDP, included high concentrations of anti-GM1, anti-GD1a, and anti-GD1b antibodies, which may account for his severe disease course.
\end{abstract}




\section{Case Reports in Neurology}

\section{Introduction}

While Guillain-Barré-Strohl syndrome (GBS) is usually monophasic, $10 \%$ of patients will deteriorate after an initial response to treatment, known as a treatment-related fluctuation (TRFs) [1]. TRFs should be differentiated from acute-onset chronic inflammatory demyelinating polyneuropathy (A-CIDP), a condition where symptoms evolve over at least 8 weeks in a progressive, stepwise, or relapsing course. Five percent of patients initially diagnosed with GBS actually have A-CIDP and 16\% of patients with CIDP present with an acute GBS-like presentation [2,3]. Distinguishing between GBS-TRF and A-CIDP is critical as patients with ACIDP require long-term immunotherapy.

While patients with GBS-TRFs tend to be more severely affected (including cranial nerve involvement), GBS-TRFs occur no more than twice and exclusively within the first 8 weeks after diagnosis [2]. Antibodies to gangliosides, such as anti-GM1 IgM, have been described in A-CIDP and other chronic neuropathies, but are found in lower percentages than in GBS [4]. Ganglioside antibodies bind to neuromuscular nerves at the nodes of Ranvier and induce complement to form membrane attack complexes at the nerve terminal, thereby causing failure of the axonal membrane to maintain ionic potentials [4]. Absence of treatment may lead to secondary axonal degeneration.

\section{Case Presentation}

A 25-year-old man presented with bilateral lower extremity weakness that progressed gradually after 2 weeks of upper respiratory symptoms. He was unable to ambulate. Examination of the lower extremities showed 3/5 strength bilaterally, absent Achilles and patellar reflexes, and decreased sensation to light touch to the level of the knees. Cerebral spinal fluid (CSF) showed protein of $49 \mathrm{mg} / \mathrm{dL}$ with normal cell counts and glucose. Electromyography/nerve conduction studies (EMG/NCS) reported prolongation of F-wave latencies and absence of sensory nerve action potential initially, consistent with a demyelinating process. He was diagnosed with GBS, treated with intravenous immunoglobulin (IVIG), and returned to baseline.

One year later, the patient presented with recurrence of bilateral lower extremity weakness that progressed over several weeks after diarrheal illness. He had difficulty ambulating and slurred speech. Exam showed absent reflexes in the lower extremities, decreased sensation in the legs, and a waddling gait. CSF showed elevated protein of $75 \mathrm{mg} / \mathrm{dL}$. He was treated with supportive care. Following acute rehabilitation, he estimated he was able to recover to $80 \%$ of his baseline and could ambulate with a cane.

Three years after initial presentation, he presented with worsening quadriparesis. He was unable to move out of his bed. He received IVIG treatment but his weakness progressed. He was discharged to rehabilitation, then readmitted to the hospital with an ileus. He required intubation due to neuromuscular weakness. He was transferred to our neurocritical care unit where neurological exam showed intact extraocular movements, upbeating nystagmus, facial diplegia, decreased tone, and fasciculations in the lower extremities. At best, he could move his extremities slightly with gravity eliminated. Sensation was diminished to pinprick in a patchy distribution in a length-dependent manner without a clear sensory level. Proprioception was impaired at the big toe but present at the ankle and vibration sense was mildly impaired. The plantar reflex was absent. The patient was areflexic.

\section{Karger'=}




\section{Case Reports in Neurology}

Case Rep Neurol 2021;13:72-76

\begin{tabular}{l|l}
\hline DOI: 10.1159/000511956 & $\odot 2021$ The Author(s). Published by S. Karger AG, Basel
\end{tabular} www.karger.com/crn

Patnaik et al.: A Severe Course of Relapsing-Remitting Acute-Onset Chronic Inflammatory Demyelinating Polyneuropathy in a Young Man

Workup for monoclonal proteinopathy was negative, including a vascular endothelial growth factor level. He tested negative for antibodies associated with celiac disease, Sjögren syndrome, and systemic lupus erythematosus. Homocysteine level was slightly elevated (13 $\mu \mathrm{mol} / \mathrm{L}$ ) but vitamin $\mathrm{B}_{12}$ was above $1,000 \mathrm{pg} / \mathrm{mL}$. Genetic testing for congenital disorders of glycosylation was negative. Alpha-galactosidase was normal, making Fabry disease unlikely. Infectious workup for HIV, hepatitis C virus, West Nile virus, Lyme disease, EBV, and CMV were negative as was heavy metal testing. Beta-2 microglobulin was slightly elevated but PET/CT showed no evidence of malignancy. High-density lipoproteins were within normal limits, making Tangier disease less likely. Urine porphobilinogen was within normal limits.

Repeat EMG/NCS revealed a purely axonal pattern with abnormalities in motor and sensory potentials, either reflecting secondary axonal loss due to progressive, untreated demyelination or a primary axonal neuropathy. CSF revealed a normal white blood cell count and elevated protein of $107 \mathrm{mg} / \mathrm{dL}$. Spine magnetic resonance imaging (MRI) showed nerve root enhancement at the cauda equina (shown in Fig. 1). Sural nerve biopsy revealed loss of myelinated axons, and a few remaining degenerated axons with greater loss of the large axons (shown in Fig. 2). Serum was strongly positive for ganglioside IgG/IgM antibodies: anti-GM1, anti-GD1a, and anti-GD1b. He completed a course of plasma exchange and a 5-day course of methylprednisolone. He was then placed on high-dose daily prednisone and transitioned to cyclosporine. Eight months later, his strength had improved to $4 / 5$ strength in the bilateral upper extremities with $2 / 5$ strength in the bilateral quadriceps and tibialis anterior and 3/5 strength in the bilateral gastrocnemius.

\section{Discussion and Conclusion}

A-CIDP can be associated with blood dyscrasias, cryoglobulinemia, or amyloidosis. Other inflammatory neuropathies considered in this case included sarcoidosis, Sjögren syndrome, rheumatoid arthritis, systemic lupus erythematosus, celiac disease, and systemic vasculitis. Infectious possibilities included HIV, Lyme disease, West Nile virus, and hepatitis $\mathrm{C}$ virus but were less likely given the initial improvement without treatment. Toxins, including heavy metals such as arsenic and lead, and genetic etiologies such as Tangier disease or Refsum disease, were also considered but would more likely present with a steadily progressive course. The recurring course raised the possibility of porphyria, though urine porphobilnogen were unremarkable.

In A-CIDP, features of EMG/NCS include conduction slowing evidenced by prolongation of motor distal latencies, reduction of motor conduction velocities, or prolongation of $\mathrm{F}$-wave latency. Demyelinating parameters would also be defined by absence of F-waves in two nerves or partial motor conduction block [5]. Other features are elevated CSF protein, nerve biopsy showing unequivocal evidence of demyelination, or MRI showing enhancement of the cauda equina, nerve roots, or brachial or lumbosacral plexuses [5]. Anti-GM1, anti-GD1a, and antiGD1b are known to be prominent in acute motor axonal neuropathy, a variant of GBS, but have also been seen in CIDP variants [4].

Like in our patient, anti-GD1a and anti-GM1 antibodies have been associated with preceding diarrheal illness especially with $C$. jejuni [6]. Anti-GD1a antibodies and anti-GM1 antibodies may be pathogenic in development of axonal neuropathies and associated with severe disease course [6, 7]. Anti-GD1b antibodies may be rarer in patients with CIDP, but in patients with GBS, the coexistence of anti-GD1b and anti-GM1 antibodies predicts delayed recovery

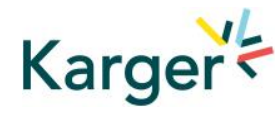




\section{Case Reports in Neurology}

\begin{tabular}{l|l}
\hline Case Rep Neurol 2021;13:72-76 \\
\hline DOI: 10.1159/000511956 & $\begin{array}{l}\text { (c) 2021 The Author(s). Published by S. Karger AG, Basel } \\
\text { www.karger.com/crn }\end{array}$ \\
\hline
\end{tabular}

Patnaik et al.: A Severe Course of Relapsing-Remitting Acute-Onset Chronic Inflammatory Demyelinating Polyneuropathy in a Young Man

when compared to the presence of anti-GD1b antibodies alone [8, 9]. We posit that co-occurrence of anti-GM1, anti-GD1a, and anti-GD1b antibodies combined with lack of ongoing immunotherapy caused a "nodopathy" in our patient with secondary axonal degeneration, accounting for his fulminant course.

\section{Statement of Ethics}

The research was conducted ethically in accordance with the World Medical Association Declaration of Helsinki. Subject has given his written informed consent to publish his case including publication of images.

\section{Conflict of Interest Statement}

The authors have no conflicts of interest to declare.

\section{Funding Sources}

The authors received no financial support for the research, authorship, and publication of this article.

\section{Author Contributions}

Anna P. Patnaik: drafted, edited, and revised manuscript. Joseph Mininni: acquisition and analysis of pathological data. Neil C. Porter: edited and revised manuscript. Nicholas A. Morris: drafted, edited, and revised manuscript.

\section{References}

1 Kleyweg RP, van der Meché FG. Treatment related fluctuations in Guillain-Barré syndrome after high-dose immunoglobulins or plasma-exchange. J Neurol Neurosurg Psychiatry. 1991 Nov;54(11):957-60.

2 Ruts L, Drenthen J, Jacobs BC, van Doorn PA; Dutch GBS Study Group. Distinguishing acute-onset CIDP from fluctuating Guillain-Barre syndrome: a prospective study. Neurology. 2010 May;74(21):1680-6.

3 McCombe PA, Pollard JD, McLeod JG. Chronic inflammatory demyelinating polyradiculoneuropathy. A clinical and electrophysiological study of 92 cases. Brain. 1987 Dec;110(Pt 6):1617-30.

4 Kaida K. Pathogenic roles of antiganglioside antibodies in immune-mediated neuropathies. Clin Exp Neuroimmunol. 2013;4(1):60-9.

5 Joint Task Force of the EFNS and the PNS. European Federation of Neurological Societies/Peripheral Nerve Society Guideline on management of chronic inflammatory demyelinating polyradiculoneuropathy: report of a joint task force of the European Federation of Neurological Societies and the Peripheral Nerve Society First Revision. J Peripher Nerv Syst. 2010 Mar;15(1):1-9.

6 Shahrizaila N, Kokubun N, Sawai S, Umapathi T, Chan YC, Kuwabara S, et al. Antibodies to single glycolipids and glycolipid complexes in Guillain-Barré syndrome subtypes. Neurology. 2014 Jul;83(2):118-24.

7 Kaida K, Morita D, Kanzaki M, Kamakura K, Motoyoshi K, Hirakawa M, et al. Anti-ganglioside complex antibodies associated with severe disability in GBS. J Neuroimmunol. 2007 Jan;182(1-2):212-8.

8 Taams NE, Notermans NC, Fokkink WR, Tio-Gillen AP, Huizinga R, Schreurs MW, et al. Clinical relevance of serum antibodies to GD1b in immune-mediated neuropathies. J Peripher Nerv Syst. 2018 Dec;23(4):227-34.

9 Ang CW, Yuki N, Jacobs BC, Koga M, Van Doorn PA, Schmitz PI, et al. Rapidly progressive, predominantly motor Guillain-Barré syndrome with anti-GalNAc-GD1a antibodies. Neurology. 1999 Dec;53(9):2122-7.

\section{Karger'=}


Case Reports in Neurology
Case Rep Neurol 2021;13:72-76

DOI: $10.1159 / 000511956$

(c) 2021 The Author(s). Published by S. Karger AG, Basel www.karger.com/crn

Patnaik et al: A Severe Course of Relapsing-Remitting Acute-Onset Chronic Inflammatory Demyelinating Polyneuropathy in a Young Man

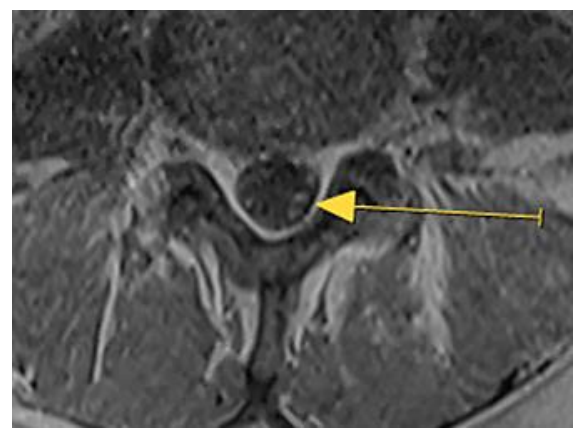

Fig. 1. MRI of lumbar spine. Axial T1 post-gadolinium showing contrast enhancement of cauda equine nerve roots (yellow arrow).

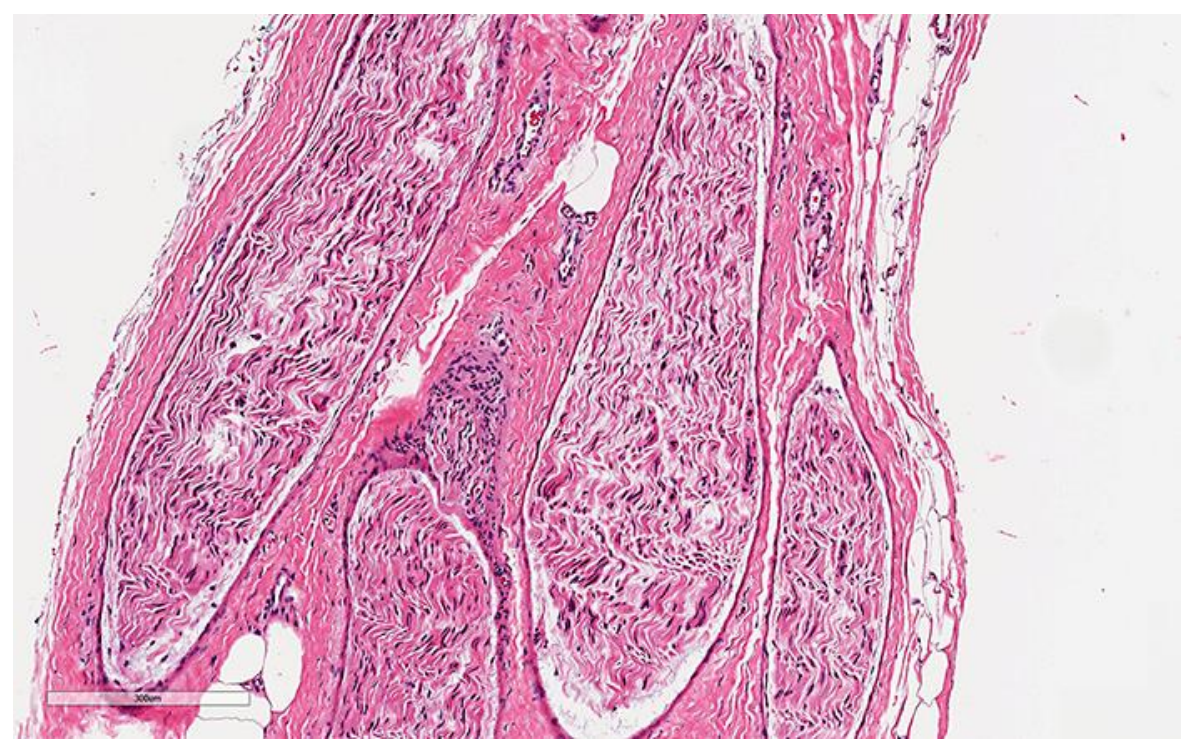

Fig. 2. Sural nerve biopsy. 10×. H\&E stain. Nerve biopsy revealing multiple peripheral nerve fascicles with decreased cellularity and mild fatty infiltration. 